\title{
PERSPECTIVA DA ÚLTIMA GERAÇÃO NA NOVELISTICA NORTE-AMERICANA
}

Heriberto Arns

O editor norte-americano Alfred Knopf, de New York, quando esteve no Rio de Janeiro, a última vez, foi abordado pelo repórter do "Globo" sôbre a situação da novela americana. Estava acompanhado de sua senhora que se julga também autoridade em matéria de lançamentos de novelas. A entrevista culminou com a frase: "A novela vai mal, de um modo geral, no mundo inteiro, e a nova geração de escritores dos E.U.A. não produziu ninguém da dimensão de $E$. Hemingway, Fitzgerald, Sinclair Lewis". Uma pequena ressalva à mediocricade da novelística atual foi feita quando a Sra. Knopf, atenuando a opinião de Alfred, opinou que John Updike e J. D. Salinger são excelentes escritores. Embora se trate da opinião de editores apenas, a entrevista espelha uma realidade também do ponto de vista crítico-literário. Do ponto de vista comercial, o livro talvez não vá tão mal, porque muitas novelas percorrem o processo comercial em voga: edição normal, edição "pocket-book", edição em clubes de livros, teatro, cinema, musical, às vêzes, e tradução. A. Knopf cita alguns escritores que fizeram um milhão, nessa trilha: Harold Robbins, Leon Uris e Fast. A promoção do autor e do livro junto ao grande público leitor faz-se hoje por fórmulas bem testadas. A autenticidade e o valor literário não dependem, no entanto, de fórmulas de pura comercialidade. $\mathrm{E}$ aí surge a dúvida sôbre a continuidade da liderança americana nas letras, indiscutível na década de vinte a trinta.

Com o desaparecimento de Hemingway e Faulkner, estão a eclipsar as últimas estrêlas do grande renascimento das letras americanas. Dos grandes nomes do século, que representam uma liderança na literatura, poucos restaram e muito poucos novos valores prometem levar avante a liderança que 
há poucos decênios se afigurava inquestionável na novelística. $\mathrm{Na}$ poesia igualmente desapareceram os grandes. Acabam de morrer Robert Frost e Robinson Jeffers. Mesmo no drama os expoentes são os mesmos de há decênios atrás. Seriam êsses desaparecimentos, o fim dum grande ciclo que mereceu ser chamado a "Renascença Americana do Século XX"?

A literatura dos últimos decênios traz a característica de uma experiência. Desde que a América iniciou sua projeção nas Letras, ela o fez com tôdas as características de lançar algo de nôvo, sem pretensões de atingir uma meta definitiva. Como o teatro moderno adicionou muitos instrumentos introduzidos por especialistas em côr, desenho e eletrônica, assim a novelística americana experimenta novas técnicas como quem sente a necessidade de atualizar a sua linguagem para ser compreendido.

William Faulkner constatando que "nós todos fracassamos", encontra uma pequena, mas significativa desculpa para Wolfe na limitação de sua curta vida. Ao fim da vida de Wolfe, constatou-se que seu editor mandou um caminhão para transportar seus manuscritos inéditos. Um táxi devolveu-os e algumas centenas de páginas apenas, revelam ao mundo a última mensagem do jovem escritor. Talvez fôsse essa a sorte desta arrojada, dinâmica, vivída geração da grande experiência literária americana que representa hoje mais uma prometedora perspectiva que retrospectiva, porque ela é, em última análise, uma geração de experimentadores. A grande verdade que Wolfe descobriu aos 29 anos interpreta tôda uma geração de escritores: "Meu livro procura descobrir a razão por que os americanos constituem uma raça nômade, por que são aniniados por uma saudade obscura e dinâmica onde quer que se encontrem, em seu próprio país ou no estrangeiro". Aos 30 anos Wolfe completa o seu pensamento: "Julgo que finalmente começc a me capacitar adequadamente a usar o material de que o escritor se vale, pois parece-me que êle deve ver naquilo que the acontece, elementos da experiência universal". $E$ ainda na obra que não chegou a terminar: "The Hound of Darkness", sua afirmação se torna palpável: "Será uma sinfonia tonal da noite, plataforma de estação de estrada de ferro, locomotivas, trens de carga, desertos, cascos troteando, etc., 
apreciado por uma personalidade definida, dominada inteiramente pela percepção de uma personalidade".

As grandes experiências do século, vivídas na América e pela América, registradas pela literatura dos últimos decênios, são as experiências das gerações que combateram sem acreditar na guerra, experiências das vítimas do passado e do presente e do progresso da América.

\section{THE LOST GENERATION}

Quando Stephen Crane tomou emprestado o necessário dinheiro para publicar 700 cópias duma novela, êle o conseguiu com a condição de que o nome Crane não fôsse mencionado na edição de "The Red Badge of Courage". Embora recebida por número limitado de leitores, apresentava características duma experiência de uma nova geração consiclerada digna de estudos. Henry Flaming inicia com seu "Why? Why?" uma nova surpreendente atitude na novelística da guerra, fazendo a terrivel descoberta que "He had been to touch the great death, and found that, after all, it was but the great death. He was a man". Não é a guerra que se torna uma experiência; experiência torna-se a descoberta do homem, tanto no seu heroísmo como na sua covardia. O sentido da guerra, da batalha, da vitória, se converte em Henry Fleming naquilo que o homem é na sua vida, na sua consciência de "craven coward" ou de "magnficent hero". Esta consciência do soldado que viveu a batalha despida de ilusões, consciente do desafio que as contingências do perigo dirigem ao seu valor, vamos encontrá-la, desde então, em homens desiludidos que voltam da guerra para nunca mais acreditar na grandeza do homem.

Crane, desaparecido na curva do século, legou à geração de escritores intérpretes das duas grandes guerras mundiais, um protótipo.

O F. Henry de Hemingway não herda apenas o nome Henry, de Crane, toma-lhe por herança as atitudes, a própria consciência do desencanto, como a grande maioria dos heróis hemingwayanos. A "Lost Generation", que Gertrude Stein descobriu nas páginas do jovem Hemingway nasceu em "The Red Badge of Courage", que precedeu a tôdas as novelas que des- 
crevem a guerra como uma grande oportunidade para a revelação do cinismo humano. Faulkner em "Soldier's Pay", John dos Passos em "Three Soldier's", Remarque e Mailer, descrevem o mesmo triste produto humano da guerra. "The Roaring Twenties", foi o decênio em que a "Lost Generation" experimentou eudaimoniacamente os fascínios do cinismo. a geração dos "The beautiful and damned". A "extravaganza" ameaça transformar-se em "American Way of Life". Em Fitzgerald a "shattered and demoralized civilization", vivída ou adotada pela geração perdida, procura ambientes cosmopolitas, ligando as capitais do "Jazz Age": New York, Paris e Riviera. Sofisticam-se atitudes, invertem-se valores, desprezamse standards e códigos, proscrevendo-os como tabus. O encanto do amor e da morte decaem a nivelar-se com o desencanto do beber e da violência. Surge a experiência de uma linguagem nova, da "flaming youth, flippant and hardboiled" para quem "sport and sex, liquor and smoke, cynicism and despair" constituem se não um sentido, ao menos uma quimera sedutora da existência, "dêste lado do paraíso". A mocidade vive o carnaval de uma época de uma coloração exuberante, mas dum fim que não interessa. $O$ dólar americano toma proporções e fascínio de infinito para uma geração que para viver o presente, resolveu desconhecer o passado e o futuro também. O fascínio da riqueza é absoluto na noite da orgía mesmo quando o desencanto se anuncia antes da aurora. a revolta duma geração a quem se fêz acreditar no heroísmo e na dignidade da guerra. a geração que Stephen Crane viu nascer na guerra civil e personificou em Henry Fleming. Foram assim tôdas as gerações que tiveram que viver a primeira fase de sua vida, e a mais bela, a mais generosa, na guerra em que foram obrigados a acreditar e que, terminada, lhes pareceu estúpida e um hiáto sem fim entre a primeira e a segunda metade da vida que não tinham coragem de começar. Hemingway sentiu, experimentou êste hiato nihilista. Para êle a vida foi então uma frustração no escuro, onde o jovem não mais sente um incentivo da escolha, e, por isso, da iniciativa de recomeçar. A primeira atitude de Hemingway, no entanto, apresenta um ponto de resistência: o estoicismo. Hemingway sugere a atitude de resistir, de conquistar uma calma heróica ou de sucumbir lutando. Hemingway e Dos 
Passos sugerem a arte como refúgio e, talvez, como um sentido, em meio às absurdidades da Existência. É a sua "out-of-door existence". Nessa existência o artista se torna intérprete das experiências duma geração marcada, de sua grande fome e de sua grande sêde que, não tendo onde procurar solução, se externam no sexo e na violência. Os "inner drives of life" encontram um culto e festejam uma apoetose que Hemingway não procura justificar, mas intrepretar em "The Sun also Rises". O estocismo de Hemingway diante da crueza da existência, desenvolve-se do nihilismo a uma perspectiva moral de valores. Em "To Have and Have Not" nasce a consciência social. Os problemas morais surgem à procura de equações.

Quando o herói morre constatando que êle isoladamente não tem vez, mas que juntamente com as outras vitimas da scciedade terá um direito no mundo, surge a idéia da comunidade. Aos fundamentos físicos admite, Hemingway, bases éticas. Em "For Whom the Bell Tolls", a idéia da comunidade ganha terreno. O homem não vive só, mas faz parte da humanidade. A vida continua violenta, mas o homem encontra razões para vivê-la estòicamente e, talvez, heròicamente. $O$ homem deve viver para todos. $O$ espirito de camaradagem começa a colocar-se em bases éticas superiores. Os sinos metafísicos de Donne começam a soar para o naufrágio do séc. XX.

Santiago em "The Old Man and the Sea", foi longe demais para aprisionar o "gigantic marlin". E, transpostos os limites da contingência do pescador, êle se viu sujeito a tôdas as fôrças destruidoras, mas permaneceu alevantado quando tomou consciência de que o homem pode ser ferido e até destruído, mas nunca derrotado, enquanto permanece intransigentemente sincero consigo mesmo. $\mathrm{E}$ mesmo deitado com os braços estendidos, em forma de uma cruz, êle continua com o direito de sonhar. As experiências da geração interpretada por Hemingway culminam, afinal, na verificação da transcendência da luta. $O$ artista não se satisfaz com as experiências apenas "Dêste Lado do Paraíso", mas, ao final da luta, êle viu muito mais "there, ahead, as he could see, as wide as all the world, great, high, and unbelievable white in the sun, was the square top of Kilimanjaro. And then he knew that was where he was going". O artista descobriu, e certamente foi esta a 
sua maior experiência que "Its summit is called the Masai Ngàje Ngài-the House of God". Abaixo do último cume fôra encontrado a ressequida e congelada carcassa de um leopardo. E Hemingway acrescenta "No one has explained what the leopard was seeking at that altitude". Hoje que os expoentes da "The Lost Generation", desaparecem, evidencia-se mais e mais quanta razão tinham para interpretar experiências e vivências duma geração que perdeu seu norte numa civilização marcada pela violência e pela estupidez da guerra e pela vacuidade duma paz que não soube restaurar a dignidade do indivíduo e o sentido da existência através do solidarismo humano e dos ideais que resistem não à destruição, mas à derrota.

\section{A TRÁGICA AMÉRICA}

Otimismo foi a nota característica da literatura da Fronteira. O homem da fronteira tomou a si a épica missão de realizar uma civilização em que êle pudesse, por sua vez, realizar-se a si mesmo. O homem da fronteira é o homem confiante na sua própria capacidade. Os obstáculos todos seriam elementos a mais para a grandeza da realização de suas metas. Pouco esperou da Europa, tudo esperou da América. Enquanto o "American Dream in Action" conduzía as grandes massas do Atlântico ao Pacífico, o "Pioneer Spirit" não admitia crises de confiança na magna tarefa. Quando, no entanto, a tarefa estava terminada, o solo conquistado, as massas humanas distribuidas, iniciou-se um grande movimento de retôrno. A industrialização iniciou o movimento de retôrno das massas que o sonho pioneiro distribuira sôbre o mapa virgem da América. O sonho f́́ ra a grande válvula de escape para os obstáculos que pudessem surgir. O retôrno das populações desiludidas que a indístria começava a concentrar em grandes centros, criariam cunflitos que caracterizariam a nova época do desenvolvimentc americano. Os ciclos de pânico, iniciados em 1873 e as frequc ates depressões representam eclosões de conflitos de estruturas que a América só iría dominar após tremendas experiêlıcias nacionais. O "American dream" transformava-se para milhões em "American nightmare". A literatura seria a intérprete desta experiência trágica da América. Se a literatura pioneira foi uma auto-afirmação americana, 
porque tôda a sua grandeza provinha da América - o novo período dos confitos sociais faz parte do ciclo duma crise mundial. A crise americana faz parte da crise de tôda uma civilização. Daí o caráter mais e mais cosmopolita desta literatura americana.

A literatura :omântica dava acento a duas categorias de caracteres: os bons e os maus. A nova literatura cria novas categorias: os for tes e os fracos. A literatura romântica lutava pela vitória dos bons e pela derrota dos maus. A literatura moderna apresenta a derrota de ambos. Theodore Dreiser publicava em 1925 "An American Tragedy" e em 1931 "Tragic America". No entanto, não era Dreiser pioneiro do pessimismo americano. Crane e Norris precederam-no. Pioneiros ambos, viveram apenas 30 anos. Crane morreu em 1900 com 29 anos de idade; Norris em 1902 com 32 anos de idade. Dreiser seria, assim, o intérprete da crise da civilização americana que êle quis chamar de tragédia. Sua interpretação trágica encontra paralelos no drama Eugene O'Neill, na poesia de Robinson Jeffers, no conto de Sherwood Anderson. O determinismo social de Taine não lhe explicam em profundidade e magnitude, a tragédia do homem da América. Quer penetrá-lo mais profundamente, sondar fôrças de ordem mais pessoal. Consulta os "Inner Drives"; e fixa as categorias de fôrças primitivas a serviço da tragédia moderna: "sex, power and greed". São as fôrças a serviço do uucesso. São os elementos que condicionam o "downfall". O miındo trágico de Dreiser movimenta-se em perspectivas Nietzscheanas: "Life is a struggle and will to power".

A filosofia de Cowperwood leva à ruina todos os esforços em prol do progresso e tôdas as vítimas a um trágico fim. $O$ ambiente é duma cunspiração social generalizada. A própria sociedade se converte em fôrça a serviço da destruição do indivíduo. Tudo reflete: conflitos tendentes à realização da grande tragédia. $O$ próprio artista se integra no ingrato conflito do mundo hostil que neutraliza a fremente genialidade do artista em luta pela autenticidade e lealdade à sua arte. A destruição impulsionada como que por uma monstruosa máquina que é a sociedade ou por monstros humanos que são os indivíduos, lembram "The Dynamo" de Henry Adams, sem atingir a consciência da tortura revelada em "Chaos", em atitudes de 
estúpido agnoticismo. Karl Marx vem pregar panacéias para curar a enfêrma terra do Leatherstocking. Marx, Nietzsche e Freud que tanto mexeram com o sentimento e nervos mais que com a razão da intelectualidade do século $\mathrm{XX}$, surgem como espectros nos quais as vítimas e os enfêrmos parecem ser mais fàcilmente identificados. longa a lista dos "leftwing-writers". Poucos escaparam do grande contágio. Muitos fizeram da literatura um meio, não para humanizar um capitalismo e corrigí-lo nos seus excessos, mas para sugerir uma virada para a Esquerda Marxista que a geração de Upton Sinclair, Jack London, Sinclair Lewis, e mesmo Dos Passos considerava solução de um determinismo histórico irreversível.

Dos Passos, que adota a atitude cínica da "Lost Generation" e apresenta em "Three Soldiers", a desilusão ou a própria liquidação da arte pela guerra, dedica-se durante a crise dos "Twentieth", na sua trilogia, à análise da civilização americana. Não é apenas Eleanor Stoddard que procura viver o "Russian Style"; o próprio sistema social econômico americano é o vilão de "U.S.A." All Right we are two nations ... the capitalistic few and the rest". E dando ênfase à tendência, termina a U.S.A. "trilogy", deixando para trás o jovem sem ocupação e sem lar, andando pelo highway, olhando para o alto onde um enorme transatlântico transportava os bem nutridos capitalistas. "All right we are two nations".

Em 1915 foi publicada por Edgar Lee Masters, um volume intitulado "Spoon River Anthology". Iniciou-se então um ataque à vida e à sociedade de aldeias e cidades. Espírito tacanho de intrigas, de hipocrisias, caracteriza a nova interpretação que lhes dão Masters, Anderson, Ludwig Lewisohn e Sinclair Lewis. Desaparecera o "folk spirit" para dar lugar à "conformity", "social standardization". As massas outrora imbuidas dum sadio espírito de aventuras, constantemente dinamizadas para a conquista, detinham-se agora. A contabilidade industrial garantia-Ihes a conquista. Este novo prisma duma jovem geração de escritores vem representar uma fôrça a mais do iconoclasmo com que se tratam as coisas americanas e humanas. Predominam nesta literatura os "surface phenomena". Gopher Prairie torna-se um símbolo do "small-town mind". Babbitt é a figura típica do "middle-class business man", êle o "prosperous real-estate broker". Em "Arrowsmith" Lewis apre- 
senta em maravilhosos contrastes o comercialismo que se pratica com a doença e a pobreza. Suas novelas, abordando impressionantes fenômenos da civilização, mas desprezando valores e os próprios fundamentos do agir humano, revelam uma tônica duma inconformidade que dita soluções radicais. Como repórter dos males de urna época da história americana, prega, Lewis, uma cruzada paia soluções drásticas sem dizer onde a América iría encontrá-las. As experiências que cata nas vilas, cidades e classes profissionais, não sugerem como humanizar, não sugerem fontes de novas inspirações nem as bases sempre verd́adeiras para a reforma do indivíduo e da sociedade. Tudo atira à generalização, "mass of dullness". Mesmo o problema religioso, vital e básico para qualquer reforma, lega à trivialidade voltairiana: "dullness made God".

Entre os "left-wing-writers" destaca-se o "hard-boilèd" Caldwell. Durante o segunda guerra mundial, êle procurou Moscou, como correspondente de guerra. Os problemas da mortalidade infantil, da subnutrição, da fome, da ignorância, da superstição, da frustração, Caldwell coloca em contraste com a bem nutrida, intelectualizada, civilizada classe de americanos. Os males do sistema capitalista servem-lhe à indignação contra todo um sistema. Os "poor whites" nas pobres terras do sul procuram substitutivos em religião e sexo e em práticas extralegais para seus males. Seu humor naturalístico dissolve o conteúdo trágico. Seu primitivismo, ao apresentar a brutalidade e o terror dos instintos humanos, por vêzes se funde num simbolismo que estimula o leitor a pensar adiante $e$ tomar consciência do problema mesmo em meio a situações trági-cômicas. As experiências que colhe entre os "poor whites" de Georgia, apresenta-as, Caldwell, em imagens grotescas, como escritor da tradição naturalística.

Declinando o epíteto de comunista ortodoxo, mas aceptando o marxismo como credo literário, James T. Farrell desenvolve seus temas na tradição naturalística de Theodor Dreiser. Ocupa-se com a grande cidade e a sociedade capitalística. Não deixa dúvidas sôbre as bases marxistas de sua concepção. As estruturas sociais econômicas condicionam a conduta da sociedade e determinam atitudes do indivíduo. A urdidura de sua obra novelística, brota das experiências de sua própria vida e lá procura os aspectos mais sórdidos da vida cidadina, 
violência, sexo, desajustamento familiar, estreiteza religiosa, rivalidades políticas e tudo que oprime uma sociedade em fase de desintegração. A falência dos valores desta sociedade suprime a própria generosidade e a esperança de seus jovens. A frustração dos sonhos marca a nova geração, principalmente quando não compreendida pela mais velha em suas aspirações. E tudo, Farrel procura documentar. A própria religião é apresentada como uma escravidão da civilização que impera. Sua trilogia Studs Lonigan descreve as experiências dum jovem que quer ser apenas "one of the boys", cujos impulsos sadios são reprimidos pelo ambiente para, durante os anos da guerra mundial, adotar a conduta da geração corrupta. O último volume "Judgement Day" conta os últimos anos do jovem, sua enfermidade, seu último amor e sua completa frustração, ao morrer aos 30 anos de idade. Farrel é o repórter e o intérprete das experiências da mocidade, na familia e nas ruas. Sob influência de Dreiser, Joyce e Proust, Farrel apresenta atitudes e estados de espírito que nascem da complexidade das transformações sociais e do marginalismo da civilização. São também experiências e como tais merecem o respeito principalmente quando trazem as marcas da autenticidade biográfica do escritor que relata suas próprias crises que se estendem até a idade sexagenária.

\section{"THE ROUGH" - VelHo E Nôvo Marginalismo No Oeste}

O extremo Oeste despertou a atenção, não apenas pela fascinação das minas de ouro, mas pelo tipo humano que sentiu sua atração e soube formar, na hora da ilusão e desilusão, uma camaradagem dentro e fora da lei. Bret Hart descobriu 0 "diamond in the rough and the prostitute with the heart of gold". Os "outcasts" de Bret Hart nunca mais morreram porque representam um misto de primitiva inocência, heroismo, generosidade e marginalismo.

A criança que nasceu no "Roaring Camp" em 1850 como filho da prostituta Cherkee Sal em meio aos "tough hombres", realiza, pela mera presença, uma transformação. A presença de Tommy Luck exige uma limpeza da cabana e das próprias vestes dos marginais. Mesmo o mais abrutalhado entre êles se enternece ao ver e tocar o menino. Uma criança do pecado 
exerce uma reação regeneradora. $\mathrm{Na}$ inconsciência do crime desperta repentinamente a consciência da bondade. A criança despertou nesses homens, sem lar, o primitivo instinto da família. Os próprios viciados do jôgo, da violência e do furto, tornam-se atentos à voz interior, nas decisivas horas e pronunciam sabedoria de inefável beleza. Estes hombres de Bret Hart, mistos étnicos e éticos, compostos de sangue, de raças, de costumes, de tradições, de vícios, e de virtudes, povoam a literatura numa tradição de Bret Hart, Willa Cather, Catharine Anne Porter e John Steinebck. Estes homens são diferentes. Conhecê-los e interpretá-los é uma experiência. Suas virtudes, seus vícios e seus crimes parecem um mito. Estes caracteres situam-se numa civilização diferente. $O$ hispânico, o mestiço, o indio de cultura espanhola foi sempre atração para o intelectual "Anglo-Saxon". Willa Cather descreveu com entusiasmo os Indian pueblos na novela de pioneirismo religioso newmexicano: "Death Comes for the Archbishop".

Catherine Anne Porter sentiu-se atraída pela jovem $\mathrm{Ma}$ ria Conception. Em "Flowering Judas", Catherine situa a jovem americana Laura entre os revolucionários mexicanos "Laura is not at home in the world". E um mundo diferente, violento, criminoso, mas por vêzes insconsciente do crime, mundo êsse que deve ser interpretado não tanto pelas ações de seus personagens como pelas intenções dos protagonistas. Catherine Porter procura inteirar-se dêste mundo estranho através do mito religioso. Não usou os mesmos meios Graham Green, quando quis descobrir o Poder e a Glória de Deus no trapo humano que, na hora da graça da revolução mexicana, se transformou em herói? Steinbeck, o californiano, retoma as experiências da vida atrativa, inconvencional do pitoresco povo de sangue espanhol ou mexicana ou indio que formam os paisanos da Califórnia. Explora as atrações do primitivismo da superstição, do mito, do homem que se identifica com a terra pelo sacrifício que, às vêzes, vai até a auto-destruição. $O$ ambiente forma-se fora da civilização. Os códigos são outros, as aspirações são outras. Em meio à violência permanece a aura da humana simpatia. A pobreza, a ignorância, a violência, frustração dos grupos, contribuem para o solidarismo que se forma contra a civilização que admitiu a injustiça econônica e social. O mundo dos paisanos vive a fé no próximo sem es- 
peranças em relação ao futuro. O mistério do amor humano, externado na forma mais primitiva, é o único fundamento que ficou para tornar os marginais dignos da vida que levam. $O$ mundo paisano e seus tipos é o mundo distante, cheio de grandeza e sabedoria. Há nêles, por vêzes nos tipos mais ordinários, a sabedoria quasi omniscente que lhes comunicam a dôr e o desespêro da pobreza, a frustração e a humana desesperança. 0 "happy-go-lucky people" que reune o trágico e o cômico, vive à margem duma civilização, sôbre cujos códigos se sente êle autorizado a pronunciar se não o veredito, mas palavras de primtiva sabedoria. Nos vales "Salinas" revive, um povo, a vida primitiva, gerações de Cains e Abeis, de homens marcados na testa pela violência, no coração pelo perdão dum processo constante de regeneração cuja meta são incapazes de alcançar porque dela tem um conceito diferente daquele que a civilização se acostumou por aceitar.

A "crusading novel", "The Grapes of Wrath" descreve como a polícia, os capitalistas e a fome podem tornar miseráveis muitas vidas humanas. Como a fome induz homens ao assassino e à greve e à liderança dos que querem sobreviver. Sobrepaira a tudo a vontade de sobreviver, como característica dum povo primitivo, reduzido à escravidão de pêias com que êle não se pode conformar. Mesmo o velho, esfomeado, largado a esperar a morte, luta pela sobrevivência. Rose of Sharou, a jovem mãe, dá-lhe para amamentar os peitos que ela não pudera dar à criança recém-nascida que morreu, depois de deserdada pelo pai.

Steinbeck que, no ano de 1964, pronunciou, em Berlin, seu veredicto definitivo sôbre o sistema comunista do arame farpado, sugeriu em "The Grapes of Wrath", como um povo primitivo, não achando lugar numa civilização que não é humana nem cristã, se prepara para a reação, para a defesa, reclamando um lugar no mundo, no sistema que o quiser receber.

\section{GENTEEL TRADITION NA NOVELA FEMININA}

O romance social, na tradição de Howells e James, encontra uma expressão mais pura numa geração de escritores que abordam os temas do amor, da maternidade e da mulher den- 
tro da problemática da sociedade moderna. Howells trouxe as novas idéias da Europa para dinamizar tôda uma literatura americana. Henry James levou a experiência dum novo americano para a Europa. Criava-se a novela cosmopolita e das tradições do velho aristocracismo americano. Ambas apresentam conflitos. Conflitos no plano ético, estético e social. Edith Wharton foi protagonista dos conflitos dos códigos das aristocracias, tanto como mulher quanto como escritora. New York criara uma nova "cracia", a plutocracia, que ameaçava a soberania da dominante aristocracia e anunciava a decadência desta para impôr uma nova ordem de valores. Seu mundo é o mundo da "fifth avenue" e o resto. $O$ "social climbers" ameaçam destruir o ortodoxo "genteelism". O ostracismo é a solução de quem sucumbe na renegação da classe. Em "The Age of Innocence" aborda a dualidade matrimonial e restabelece a grandeza de seu protagonista só depois de destruidas as bases de uma humana felicidade. As 20 novelas de Mrs. Wharton apresentam uma progressiva expressão trágica das vitimas de uma "decaying order". Seus últimos contos são criações de obsessões mentais, "Tales of Man and Ghosts". No ano de sua morte em 1937, Wharton publicava a coleção "Ghosts". Uma única obra aborda ambiente rural, de New England. $E$ ainda aí seu interêsse vai ao sentido de descrever os conflitos e a decadência de quem sucumbe na luta por um momento de felicidade proibida.

Ellen Glasgow afirma a "genteel tradition" do sul, das tradições aristocráticas, dos códigos cavalheirescos, numa era de transformações das estruturas feudais. Satirizando o vitorianismo na América, cria heróis incapazes da fidelidade quando o novo ambiente convida para novas formulações de códigos. O sul depois da guerra civil é o chão de suas tragédias. Preferindo caracteres do aristocracismo sulino remanescente, Ellen Glasgow sabe tratar com carinho, homens e mulheres que surgem neste moroso despertar duma nova era. Em "The Barren Ground" a jovem Dorinda, de nascimento humilde, após a desilusão de casar o filho dum médico, procura New York. Lá encontra opoturnidade que ela regeita para voltar à terra de seus pais e heròicamente retoma a preocupação da vida do campo a que dedica sua vida procurando ser útil e encontrando no sacrifício, sua paz. Em "The Sheltered Life", 
Ellen Glasgow soube descrever, com maestria, o conflito entre as tradições do passado e a nova ordem imposta pelo industrialismo do sul. Destaca o sofrimento heróico da mulher que afirma sua grandeza ao presenciar passo por passo a tragédia em que é envolvida ao descobrir tôda extensão da infidelidade do marido. A mulher sem fôrças para resistir é condenada a sofrer a situação angustiante. $O$ código cavalheiresco dita normas dum dualismo constrangedor. Não evita a tragédia, adia seu climax para torná-la mais horrorosa. As gerações das velhas estruturas apresentam-se traumatizadas e a própria escritora, colocada entre o passado e o presente, sente o conflito entre a perda e a nova realidade.

\section{THE DEEP SOUTH}

$O$ grande renascimento americano nas letras surgiu nas décadas mais perigosas do século XX. Daí a ênfase do trágico. Dentro dêsse renascimento destaca-se, sem dúvida, a literatura do sul. Embora o caráter gótico desta literatura do sul, remonte aos tempos em que Edgar Allen Poe dirigia o "Southern Literary Messenger", êle se tornou uma herança preciosa depois que o norte plantou a bandeira vitoriosa sôbre as ruínas duma civilização admirável que foi sacrificada pela unidade americana. Desde então o trágico encontrou lá seu mais autêntico chão e em Faulkner, sua mais lídima expressão. O mundo de Faulkner é "the Deep South". Não há outro mundo. Intérprete de sua própria estirpe, dos crimes e das fatalidades de seu próprio passado, êle não protesta, não pretende condenar, mas explorar êste seu mundo horroroso nos seus ângulos e nas suas perspectivas, sobretudo nas suas retrospectivas, até encontrar a nota mais trágica em cada personagem, que é um produto ou uma parcela do mundo que é todo êle uma tragédia. Não há afirmações, há uma exploração de tôda uma genealogia. Nos "Clans" dos "Sartoris" e "Snopes" êle procura indivíduos e grupos que justifiquem seu mundo trágico que é o sul violento, lúrido, degenerado, neurótico, anormal, morônico.

O passado feudal que foi o sonho cavalheiresco de gerações, Faulkner soube transformar no "Nightmare" mais terrível da infamia, da brutalidade, de loucura, de terror, escuri- 
dão, mistério e morte, numa terrível sucessão de "suspenses". Ninguém poderia executar uma análise mais dóida, macerada no corpo e na alma de sua própria genealogia. A ninguém quis poupar, nem a brancos nem a negros, nem a ricos nem a pobres, nem a homens nem a mulheres nem a jovens. A todos atingiu a sua violência de linchamentos, de mutilações, de incestos e de assassinatos, de estupros e profanações, em vivos e mortos. Quando se esgotam todos o recursos narrativos de sua tragédia, retoma a análise e a desenvolve na mais íntima consciência de protagonistas e vítimas, dando a palavra aos que foram capazes de urdir ou de suportar a mais objetiva e horrorosa ação humana. Através dos olhos e das mentes de seus caractéres morônicos, procura atingir o âmago de seu mundo macabro. $E$ tudo isto Faulkner resume nas trágicas sagas de "Yoknapatawpha", que tem seu centro em Jefferson, nome que representa uma ironia trágica, sendo que justamente êle, Jefferson, foi o grande idealista, otimista sonhador da grandeza das colônias americanas, dinâmico filho do pioneirismo do sul. Influenciado pela tradição do "fin de siècle" e, posteriormente pela "Lost Generation", tornou-se Faulkner o mais irregular, na expressão de Robert Penn Warren, e, para muitos, o maior, da última geração.

Se uma ou outra história se nos são narradas como uma crônica íntima de uma "inocência perdida", o grande panorama é sempre "The Waste Land". Em tudo isto a voz de Faulkner é autênticamente sulina, retórica, folclórica. Depois que acabamos de ler suas histórias é que nos apercebemos de que nem tudo foi violência, corrupçāo, maldade, sacrilégio e iconocalismo, mas, por vêzes, angústia, constância, dedicação e amor. Faulkner teve razão quando, ao receber "the Nobel Prize for Literature", em 1950, caracterizou a função de escritor de nossos dias como intérprete de "the human heart in conflict with itself", que cumpre expressar "the old values, the universal truths of the human spirit". $\mathrm{E}$ afirmando um humanismo espiritualístico, expressa o destino eterno do homem que, êle só, "has a soul, a spirit capable of compassion, and sacrifice, and endurance".

Há uma diferença essencial na interpretação que Faulkner e Wolfe dão às experiências das gerações na grande tragédia 
do Sul. Ambos interpretam o passado. Faulkner apresenta uma retrospectiva sem perspectiva do futuro, demorando-se no imenso amontoado de ruínas de crimes e sofrimentos a que vê reduzido o sul. Wolfe aborda a mesma retrospectiva, demora-se nela, mas, à custa de um grande esfôrço, encontra a perspectiva do futuro, reconciliando as duas grandes fases da civilização sulina e americana. Faulkner é expressão do "deep, dark despair". Wolfe é expressão de "promise and hope". "Despair" foi a nota caracterizante da louca década de "the twentieth". "Hope" foi a característica excitante dos "thirtieth". Faulkner encaracola-se na espiral ensimesmante do sul. Wolfe, experimentadas tôdas as angústias do sul, procura a América cosmopolita e o mundo. $O$ jovem escritor, como que pressentindo que o destino lhe reservara alguns anos de experiências, lança-se a uma exploração de todos os aspectos da vida. Wolfe, saturado das frustrações da civilização sulina, lançase à tarefa de explorar os centros, onde o coração da América pulsa com maior intensidade e onde a Europa toma consciência de seus maiores conflitos. Atingindo o cume donde descortina melhor o futuro, seu pensamento se torna otimista, embora seu espírito esteja marcado pela nostalgia. Nunca, porém, coloca-se tão alto que já não veja os males do presente, que não escute os sons de alerta do futuro. Como artista, não é Wolfe um "Doctor Faustus" do passado, mas dum presente em que os conflitos das experiências o possam tornar um intérprete autêntico. Suas diagnoses não terminam, como Faulkner, no Laboratório em que tudo se analisa e onde se constata a incurabilidade dos males. Wolfe, consciente das enfermidades, manda que se procure e enfrente o futuro e se aguarde as curas maravilhosas que a esperança pode realizar. Wolfe foi sempre o anjo que, olhando para trás com olhos de criança, dispendia tôdas as suas energias para olhar para frente com olhos de jovem marcado pela dor. Hamlet americano, pergunta no vigésimo capítulo de "You Cant Go Home Again" - Que é o homem? Depois de caracterizá-lo, o homem, de criatura vil e abominável, caricatura de um sôpro desperdiçado e estéril, que morre como todos os animais e é esquecido, - Wolfe lembra-se que êle é imortal e que tanto o bem como o mal sobrevivem nêle. Seu constante conflito não permite que o trágico tome conta de sua obra. O heróico renasce-lhe sempre, 
ditando-lhe a esperança. Para a própria América e os americanos, pronunciou palavras de solidão e crueldade, mas de fortaleza e esperança também. "Embora estejamos perdidos aqui na América... seremos encontrados". O solitário menino de Ashville foi o solitário de New York e da Europa. Aí, lá e acolá, continuou a viver e narrar a sua infância perdida. Descrevendo a sua autobiografia, não fêz senão narrar experiências, vivências íntimas, suas e de sua geração, fazendo viver intensamente êste pequeno mundo de suas desilusões, deixando de pé o grande mundo de suas esperanças.

Em Wolfe vive e revive tôda insofreguidão da América, sua inquietação por tornar-se autêntica e sua esperança de não falhar na missão que descobriu. O jovem Wolfe perdeu a fé como o peregrino para quem a caminhada foi por demais exaustiva e a meta lhe afigurava por demais falaz. Mas energias ficaram para fazer renascer a fôrça da fé na realização "of our spirit, of our people, of our mighty and immortal land is yet to come". Em Wolfe renasce a epopéia Whitemaniana e a epopéia da América, depois de um periodo de ilusões, numa atitude de "recherche des temps perdu". As recordações de Wolfe não lhe brotam da memória numa atitude passiva. Elas mesmas reclamam espaço vital nas vivências que constituem as grandezas das vidas jovens e curtas, numa conjuração de "dark time that haunts us with the briefness of our days". Nesta perspectiva, Wolfe concebeu o presente e o real e o consciente. As vivências de gerações se tornam presentes na visão global do autor. O tempo, eterno como a terra e os oceanos, valoriza-se na consciência como instantes curtos da vida, nas sagas de Gant. O mundo apresenta-se em proporções invertidas, mas a perspectiva é sempre épica porque exprime experiências humanas num cenário sempre novo de cidades, rios, mares, tradição, saudades e audácias à procura de civilização.

Estamos, pois, aí de novo, após um confronto de tantas experiências da audaciosa América. Partimos de Wolfe, ao procurarmos a perspectiva desta última geração de escritores americanos, e, a Wolfe retornamos ao final destas páginas. E êle uma das vozes sinceras e, por isso, autênticas desta geração da que restam apenas alguns, ora velhos e em breve 
desaparecidos também. A América heróica do pioneirismo apresenta-se, em Wolfe, como que um protótipo de um Leatherstocking que reviveu a lenda de Rip van Winke. $O$ estranho se torna misterioso na angústia dos indivíduos que se sentiram forçados a expôr em contos, curtos ou longos, as vivências que aglutinam o passado e o presente na consciência de uma geração. Foi a imposição do gênio da América no século XX. Descobriu os deuses com os quais o homem rompe e estabelece seus conflitos. Estes deuses, foi encontrá-los sempre mais próximos de sí até identificá-los com as fôrças que êle mesmo conjurou sôbre seu espírito. 